\title{
Role of Task Repetition and Content Familiarity in EFL Students' Fluency and Accuracy in Narrative Tasks: A Case Study
}

\author{
Daniela Itzé Arredondo-Tapia, Edgar Emmanuell Garcia-Ponce \\ Universidad de Guanajuato
}

\begin{abstract}
Correspondence concerning this article should be addressed to Edgar Garcia-Ponce, Departamento de Lenguas, Universidad de Guanajuato, Calzada de Guadalupe S/N, Colonia, Centro, C.P: 36000, Guanajuato, Mexico.E-mail: ee.garcia@ugto.mx
\end{abstract}

\begin{abstract}
Developing writing skills has become a priority for many students in English as a foreign language (EFL) contexts. To this end, classroom practices should be facilitative of opportunities to communicate accurately and fluently in written and oral forms. Drawing on evidence which suggests that task repetition allows students to perform subsequent tasks more efficiently and accurately, the study examines the likely effect of procedural repetition with four narrative tasks (i.e. narrating stories in written form after watching short animated videos) on five EFL students' fluency and accuracy (AF). To do this, the levels of the students' AF were measured during the performance of each task. Moreover, qualitative data from questionnaires administered to the students after each task were also included to better understand the behavior of the AF levels in relation to their perceptions of the task performance and the familiarity with the content of the tasks. The evidence shows that the students' AF tended to progressively increase as weeks went by. The highest AF levels were found in the tasks where the content was familiar to the students. The opposite was observed when the students claimed not to be familiar with the content. The argument that we put forward in this article is that task (procedural) repetition may be beneficial for enhancing students' AF in writing task performance; however, if this practice combines with the students' lack of content familiarity, AF may engage in a dynamic interaction in which trade-off effects can be observed.
\end{abstract}

Keywords: accuracy, fluency, content familiarity, narrative task, student perception, task repetition

\section{Introduction}

Because of globalization, the need to develop writing skills to ensure academic achievement and professional success has become apparent. However, "competent writing is frequently accepted as being the last language skill to be acquired for native speakers of the language as well as for foreign/second language students" (HampLyons \& Heasly, 2006, p. 2). This could be explained by the fact that writing is a highly demanding activity which comprises complex cognitive processes (i.e. planning, decision making regarding discourse and pragmatics, making meaning to the reader, and proofreading) (Kellogg et al., 2013). Writing also demands much attention and thinking from the writer and, in contrast to spoken language, there is no opportunity for the negotiation of meaning (Kellogg et al., 2013). Despite the challenges of learning how to write in English, English as a foreign language (EFL) students are encouraged to develop writing proficiency for their professional careers and the highly competitive labor market.

To better understand the complexity of developing students' writing skills, researchers have investigated the link between writing tasks and students' complexity, accuracy, and fluency (CAF). The evidence has suggested that during writing, as well as in oral production, students tend to direct their cognitive resources to some CAF dimensions, but not all three simultaneously because of their limited attentional capacities (Robinson \& Gilabert, 2007). For example, Tavakoli and Foster (2008) conducted a study that explored the effects of narrative structure and complexity on the performance of second language students. Their results showed that the tight structure of narrative tasks is connected to increased accuracy, but narrative tasks involving background information (two storylines) increased more complex syntax. Tavakoli and Foster (2008) concluded that "L2 performance is affected in predictable ways by design features of narrative tasks" (p. 459). According to Skehan (2003), the CAF dimensions can significantly be improved when students are provided with opportunities to 
manipulate the structure and information of tasks. An implication of this is the possibility that the procedural repetition of tasks would allow students to manipulate and become familiar with the structure of tasks which are thought to be complex in nature, such as narrative tasks.

Drawing on the findings of Tavakoli and Foster (2008), we hypothesized that procedural task repetition would assist students in promoting not only accurate but also fluent written constructions in narrative tasks with a tight structure, because task repetition allows students to "access and (re)formulate words and grammatical structures more efficiently, effectively, and accurately" (Ahmadian, 2012, p. 380). Thus, the present study examines the behavior of five students' accuracy and fluency (AF) in the performance of four narrative tasks. The procedural implementation of the narrative tasks was repeated at weekly intervals using short animated videos and without controlling any classroom or student variables. Through the administration of brief questionnaires, the students' perceptions were also explored to understand their perceptions of the task performance and the familiarity with the content of the tasks. The importance of this study is that it provides an examination of the extent to which the procedural repetition of narrative tasks shapes AF levels in the students' classrooms. Moreover, this study contributes to existing knowledge on the interaction of AF in tasks whose design is complex, in other words, "the result of the attentional, memory, reasoning, and other information processing demands imposed by the structure of the task on the language learner" (Robinson, 2001, p.29). Therefore, the insights gained from this study, and particularly from the implementation of procedural task repetition, may be of assistance to EFL teachers who design writing tasks to promote their students' writing skills.

\section{Writing, Memory, and Cognitive Load}

Producing a written text is largely shaped by individual characteristics and strategies. According to Kellogg et al. (2013), writing is much more than just producing language. They believe that writing is a complex process that involves planning, making decisions, making meaning for the reader, and proofreading to make changes if needed. Some researchers in the field concerned with cognitive functions have developed models that try to unravel the processes involved in writing a text (see Flower \& Hayes, 1980; Kellogg, 1996). For example, Kellogg (1996) proposed a theory that attempted to describe the cognitive processes involved in writing, i.e. the planning of ideas, translating the ideas into written sentences, and reviewing the ideas and text already produced. In this theory, the last operation (reviewing ideas and text produced) is sub-divided into reading and editing, specifying that these required different cognitive exigencies. It is, in fact, this last operation in the process of writing that differs from oral production.

In the process of writing, it has been suggested that memory plays a key role because of its functions and capacities to perform composition activities. This assumption is supported by the stage theory model of information processing based on the work of Atkinson and Shriffin (1968). The aim of this model was to describe how memory stores and retrieves information for effective use. For Lutz and Huitt (2003), memory is a multi-staged system of representations that encompass a lifetime's accumulation of perceptions. Even though the notion of memory, its functions, and descriptions have been subject to disagreement, there is general agreement among scholars on the fact that individuals' perceptual processing is limited, and thus "to attend to a stimulus is to focus on it while consciously attempting to ignore other stimuli” (Lutz \& Huitt, 2003, p.3). Lutz and Huitt (2003) suggested that:

Attention does facilitate the integration and transfer of the information being attended, but it is impacted by many factors including the meaningfulness of the new stimulus to the student, the similarity between competing ideas or stimuli, the complexity of the new information, and the physical ability of the person to attend. (p.3)

It is implied in this assertion that memory and its attentional capacities can be influenced by other cognitive factors. This is supported by the Cognitive Load Theory, which was put forward by John Sweller in the 1980s following some principles of the information processing model. This theory suggests that there are distinct types of demands imposed on the (working) memory. These demands can be initiated by the difficulty associated with a task (intrinsic), the design or characteristics of a task (extraneous), and the presence or construction of schemas (organization of information) (germane). These demands during the performance of tasks are additive in the sense that they can individually increase the amount of processing required in the memory (Lutz \& Huitt, 2003). While intrinsic cognitive load cannot be changed, it is possible that researchers 
and language teachers can manipulate extraneous and germane cognitive loads. The implication of this for English teaching is that performing complex writing tasks and repeating their implementation design (i.e. procedural task repetition) in the language classroom will enable them to free up their extraneous and germane cognitive loads, allowing them to focus their attention on the difficulty associated with the new task (intrinsic cognitive load).

In the area of CAF, the suggestions of limited capacity of (working) memory and the nature of the cognitive load are consistent with Skehan's (2009) Trade-off Hypothesis, which argues that there is a tension between form (complexity and accuracy) and meaning (fluency) when students produce written or oral constructions. Students' inability to promote meaning and form simultaneously is believed to be a consequence of limitations in their attentional capacities, which compel them to make choices on being complex, being accurate, and/or being fluent (Skehan, 2009), and thus "committing attention to one area, other thing being equal, might cause lower performance in others" (Skehan, 2009, p. 511). These claims suggest that writing, as an activity that requires mental processing, can be highly influenced by the limited capacity of individuals' mental systems (Huitt, 2003). That is, the processes involved in writing (i.e. planning, translating, programming, executing, reading, and editing information) can use up all of the attentional capacities and thus influence their writing production in important ways. This could mean that students face the need to decide whether to allocate their attentional resources for producing either complex, accurate, or fluent compositions.

However, Skehan (2003) maintained that written and oral production can be improved if students are provided with opportunities to manipulate and become familiar with the structure and information of tasks. This suggestion becomes relevant for the purpose of the present study because it implies that repeating the design of tasks would enable students to become familiar with their structure and thus see gains in terms of the AF of their written production during tasks. To this end, we will discuss in the next section the concept of task repetition, how it has been operationalized, and its benefits for language learning.

\section{Task Repetition and L2 Performance}

At this stage, it is important to define what a writing task is. In this study, a writing task is defined as an activity that encourages students to use their language resources (e.g. meaning and form) to achieve an authentic writing objective. For more than 20 years, a practice that has gained popularity in both second language L2 pedagogy and research is the performance of writing tasks in the EFL classroom (Tavakoli \& Foster, 2008). This popularity has been motivated by the fact that through a focus on meaning, writing tasks efficiently promote the development of writing skills (Samuda \& Bygate, 2005). This learning benefit has rendered tasks as practical activities for teaching, assessing, and researching language performance and learning. In fact, research in the field of Second Language Acquisition (SLA) has corroborated the benefits of using writing tasks for language learning by examining how their design and implementation procedures (e.g. planning time, task repetition, and task familiarity) influence students' performance and learning (for a full discussion, see Manchón, 2014; Manchón \& Roca de Larios, 2011; Manchón \& Vasylets, 2019). For example, in Ellis and Yuan (2004), the effects of pre-task planning, unpressured on-line planning, and no planning were examined on the written performance of Chinese students. The results show that pre-task planning resulted in greater fluency and syntactic variety, but unpressured on-line planning led to greater accuracy. In their study, it was proposed that the two types of planning impact different aspects of L2 writing processes. Moreover, Kuhi et al. (2014) conducted a study on the effect of manipulating the type of tasks (narrative and cause-effect) on written production in English. Their findings showed that the genre of writing has an impact on the students' writing fluency and complexity, which was associated with learning styles. Together, these studies provide evidence that the planning, designing, and conditioning of tasks considerably influence students' L2 writing performance.

Because of the learning benefits of using tasks in the classroom, researchers and practitioners in the field of SLA have directed their attention towards understanding how task design and implementation procedures (of pre- and post-task activities) can maximize language performance and learning (Ahmadian, 2012). Among these variables, task repetition is a procedure that has attracted researchers' interest for more than two decades because it has been found to promote the link between language performance and development (Bygate \& Samuda, 2005). Task repetition involves asking language students to repeat the same or slightly modified tasks (the whole task or parts of a task) at intervals of one or two weeks (Ahmadian, 2012). Task repetition can also be described as repeating the same tasks with the same content or repeating tasks with the same procedure 
(procedural repetition) but with different content (Ellis, 2009). According to Ahmadian (2013) and Ellis (2005), the first performance of a task is the preparation for further performances or tasks. To handle the task at hand, this preparation allows students to simultaneously focus their attention on the message content, scan their memory, and seek appropriate language resources for use. This first encounter enables them to establish familiarity with the task and/or content. Moreover, the familiarity provides them with the basis to handle subsequent tasks more efficiently and accurately (Bygate, 1999). In Ahmadian's (2012) words, "by repeating the same or similar tasks, therefore, students might be able to build upon what they have already done in order to 'buy time' not only to do mental work on what they are about to communicate but also to access and (re) formulate words and grammatical structures more efficiently, effectively, and accurately" (p. 380). The benefits of repeating a task is that the first performance of the task will result in an activation boost and an exogenous automatic control that make the repeated task performance more efficient (Sohn \& Anderson, 2001).

Based upon the above, we can claim that task repetition is a kind of planning because performing a task one time involves implicit planning that will increase the degree of familiarity concerning the content or procedure of future tasks (Bui, 2014; Bygate \& Samuda, 2005). According to Ahmadian and Tavakoli (2010), planning opportunities - as those provided in task repetition - significantly impact the students' CAF areas. However, increasing the levels of CAF is believed to be desirable but difficult. From an information processing perspective and consistent with Skehan's (2009) Trade-off Hypothesis, Ahmadian and Tavakoli (2010) explain that this difficulty results from the fact that our attentional capacity and processing systems are both limited and selective; for example, students cannot focus on both meaning (fluency) and form (accuracy and complexity) at the same time. Consequently, students have to allocate their attentional resources by prioritizing one of these aspects of language over the others (Skehan, 1998). With the purpose of understanding how to enhance these language dimensions and minimize their trade-off effects, researchers continue to study the impact of the implementation of variables-such as task repetition-on students' language oral and written production.

To date, the impact of task repetition on L2 oral and written production has been examined in a number of experimental studies (e.g., Bygate, 1996; Larsen-Freeman, 2006). In general, these previous experimental studies have shown that task repetition can be beneficial for increasing the CAF dimensions, with some tradeoff effects being reported (Ahmadian \& Tavakoli, 2010). For example, Khezrlou (2019) investigated the effects of task repetition on learners' CAF. The students were asked to repeat a task after they received feedback in the form of corrective feedback or reformulations. His results show that the students proved to be superior in terms of accuracy and complexity. Lambert et al. (2017) conducted a study to examine the relationship between the repetition of oral monologue tasks and the L2 fluency (i.e. speech rate, frequency of clause-final and midclause filled pauses, and overt self-repairs) of 32 Japanese learners of English across three proficiency levels. They found that task repetition had a significant impact on learners' oral fluency regardless of their proficiency level. Another interesting study on task repetition was conducted by Ahmadian and Tavakoli (2010), who examined the effects of task repetition on language performance. In their study, 60 students in four condition groups (i.e. careful on-line planning without task repetition, pressured on-line planning with task repetition, careful on-line planning with task repetition, and pressured on-line planning without task repetition) were asked to watch a 15 -minute episode of a classic silent film, and then they had to explain the film under the conditions assigned for each group. Interestingly, their results indicated significant improvements in not only fluency and accuracy, but also complexity. It is important to point out that, as shown in research into task repetition, there are no consistent findings with respect to complexity and accuracy. This makes it difficult to predict if task repetition could be specifically beneficial for both language dimensions. However, it is possible to claim that through repeating tasks, students are allowed to direct their attention towards both meaning (fluency) and form (accuracy) during task performance.

Following the above, the present case study explores the potential impact of the procedural repetition of narrative tasks (i.e. narrative tasks with the same implementation procedure but with different content) on five students' AF in their classroom. We decided to investigate the procedural repetition of the tasks to better understand whether and how the students' process of becoming familiar with the design of the narrative tasks has any impact on their levels of AF. Moreover, we specifically explored the behavior of the AF areas because research evidence suggests that in unfamiliar and complex tasks that require high levels of attention, students prioritize either fluency or accuracy (Skehan, 1998), but not both simultaneously. Hence, drawing on the suggestion that task procedural repetition is beneficial for promoting the fluency and accuracy of students' 
written constructions (Ahmadian, 2012), we explore the extent to which procedural repetition shapes these two language dimensions in narrative tasks. The study is guided by the following research question:

To what extent does the procedural repetition of narrative tasks based upon short animated video input shape students' accuracy and fluency?

The importance and originality of this study come from the fact that the study and data collection took place in the students' real classroom without modifying the teaching and learning practices and the way they normally practice writing with a view to understanding the behavior of AF in this context. Moreover, it includes qualitative data to examine the students' perceptions of the tasks, their performance, and their familiarity with the tasks/content to better illuminate whether and how the procedural repetition of narrative tasks likely shapes AF.

\section{Materials and Methods}

\section{Participants and Background}

The study took place in the country of Mexico, in the central State of Guanajuato. The location was the Language Department of the public University of Guanajuato in the capital city of the state. The focus was specifically a small group of five EFL students who attended an English class for one semester in the Language Department. The English class adopted a communicative approach (according to the teacher). The students were accustomed to working in pairs and groups and sharing their work and ideas with their group. Information about the five participants will be described in detail in the following section.

We advertised our research project in the Language Department of the university. Twelve learners expressed their desire to participate in the study. Of these 12 learners, only five learners were selected for the study based on their proficiency level. Their proficiency level was measured through the Oxford placement test, which was administered by the institution at the beginning of the semester for placement purposes. The five students had a B1 proficiency level on the Common European Framework of Reference for Languages. They were five EFL students (three males and two females, all Mexicans), between the ages of 18 and 35, and with different educational backgrounds. The participants attended the English class once a week for four hours on Friday afternoons. Table 1 shows the key information of the students.

\section{Table 1}

Participants' biographical information

\begin{tabular}{lccclc}
\hline Participant & Age & Gender & $\begin{array}{c}\text { Written } \\
\text { Practice Frequency }\end{array}$ & BA and BSc Areas & $\begin{array}{c}\text { Time } \\
\text { Studying English }\end{array}$ \\
\hline P1 & 25 & M & 1 per week & Economics- Administrative & 3 years \\
P2 & 25 & M & 1 per week & Industrial Engineering & 2.5 years \\
P3 & 30 & F & 1 per week & Economics- Administrative & 2.1 years \\
P4 & 25 & M & 1 per week & Physics Engineering & 2.5 years \\
P5 & 30 & F & 1 per week & Economics- Administrative & 2 years \\
\hline
\end{tabular}

Table 1 shows the participants' biographical information, such as age (a range of 25-30 years old), gender (three males and two females), education (different BA and BSc programs), frequency of their written practice (one writing activity per week), and time studying English.

Data collected from these participants was used strictly for research purposes. As shown in Table 1 and throughout this article, participant codes are used to maintain confidentiality. The participants were aware of their right to withdraw at any time and ask for any information regarding the study.

\section{Materials}

Each of the four narrative tasks used to investigate the students' AF areas was performed at weekly intervals. The four tasks followed the same procedural implementation, that is, during each session the students watched 
a short animated video from YouTube two times to focus their attention on the content. The students were not allowed to take notes while watching the videos. After playing the videos twice, they were asked to narrate the story on paper with a time limit of ten minutes. We decided to use short animated videos because we believe that the use of animated video input to elicit written production would be interesting for the participants, making the task less stressful. The links to the videos can be found in Table 2.

\section{Table 2}

\section{Short animated videos}

\begin{tabular}{cll}
\hline Session & \multicolumn{1}{c}{ Video Name } & \multicolumn{1}{c}{ Internet Link } \\
\hline 1 & Miss Pretty Nose & https:/www.youtube.com/watch?v=YNAzHY5esBg \\
2 & Runaway & https://youtu.be/1OReXHOSnvw \\
3 & The Controller & https://youtu.be/2cBZrr2ZUsg \\
4 & Course of Nature & https://youtu.be/T78ruBKK26w \\
\hline
\end{tabular}

The videos were selected based on their length (about four minutes each) and topics. We selected these videos because they contain short stories that we thought could be familiar to the students and thus promote the AF of their written production during task performance. The four videos include dialogues in English that were level appropriate, according to the teacher of the class. Moreover, as can be seen in Table 2, the videos changed in each session; therefore, the content was different in terms of the stories they had to narrate. Based upon the suggestion that minor changes in tasks can affect learners' performance significantly (Larsen-Freeman, 2006), we acknowledge that the diversity of the stories may have influenced the results to some extent. However, our aim was to implement the tasks following classroom practices as natural as possible. Of course, this involved changing the content of the videos with a view to encouraging the students' writing production.

After each writing task, the students were asked to answer a questionnaire that functioned as a stimulated recall instrument following Fukuta's (2016) recommendation. We included the questionnaire after each task to better understand the students' task performance from their perspective and the likely impact of the procedural repetition of the tasks on their AF. The questionnaire served as stimulated recall to explore the participants' perceptions of 1) each task, 2) their own performance during the task, and 3) content familiarity. To this end, the questionnaire included five open-ended questions (see Appendix 1) because these types of questions allow the respondents to freely express their opinions without having to limit themselves to pre-determined responses.

\section{Data Analysis}

The analysis of the present study involved a combination of quantitative and qualitative data. The goal in the quantitative analysis was to identify AF patterns in each narrative task. To achieve this, we chose measures that are reported to be reliable indices representing the corresponding constructs of AF. Regarding fluency, WolfeQuintero, Inagaki, and Kim (1998) mentioned that it concerns the "number of words or structural units a writer is able to include in their writing within a particular period of time (p. 14)". Following this idea, this study considered the temporary aspect of rate, that is, the number of words retrieved in a limited time and more specifically a register of the number of words per minute (Kellogg, 1996; Ong \& Zhang, 2010). That is, we calculated the total number of words produced in each session, and then divided it by the total number of minutes for the task (10 minutes). Although we decided to use this measure of fluency, we acknowledge that this has been criticised. Skehan (1998) explains that measuring fluency is more contentious than the other dimensions (complexity and accuracy). This is explained by a high number of fluency measures that have been suggested. Nevertheless, Ong and Zhang (2010) contend that fluency in writing can be measured by calculating words produced per minute out of the total time spent on the task. Consistent with this, our study includes words per minute as being indicative of fluency because this measure indexes the students' ability to construct the length of written constructions based on the time limit assigned for the task (Wolfe-Quintero et al., 1998).

Regarding accuracy, this was analyzed through a global measure of percentage of error-free clauses. Specifically, we first identified and segmented all the clauses in each task, and then the clauses that did not contain any errors; the clauses which had errors in syntax, morphology, and lexis were excluded from the counting (Yuan \& 
Ellis, 2003). After identifying the error-free clauses, the percentages in each written production were calculated by counting the total number of error-free clauses and dividing that number by the total number of clauses, and multiplying the result by 100 . We believe that by choosing these two measures of AF, the validity of the analysis was assured because these measures have been used to investigate the link between L2 writing performance and proficiency (Wolfe-Quintero et al., 1998). Below, there is a sample of data obtained from Participant 1 in Task 3 , as well as the specific codes used to analyze the written data produced by the learners (Table 3):

/Benjamin was playing videogames/* until his mom told him/* he has/* to clean his room/*, then Benjamin's mom was trying/" to clean the controll of the videogame/ and then she was teleported into the game/*, when Benjamin realized/* that hismom is in the game/ he told her/** that they have/" to work together/" to pass all the levels in the videogame/" and then she will be free again/. Benjamin put a cheat/, later his mom beat the dragon/* and they live happy again/* playing “The controller"/*. (P1S3)

Table 3

Coding

\begin{tabular}{ll}
\hline \multicolumn{1}{c}{ Identifiable Utterances } & Code \\
\hline Correction / Hesitation & $\underline{\text { Word }}$ \\
Clause & $/$ \\
Error-free Clause & $*$ \\
\hline
\end{tabular}

It is well noted in this sample how the clauses and the error-free clauses were identified and classified to later calculate accuracy globally. The number of words per minute were also counted and listed as an attempt to measure fluency. Below, Table 4 shows how the results from the coding and calculations were gathered for analysis.

\section{Table 4}

Accuracy and fluency in Task 3 (P1)

\begin{tabular}{ll}
\hline \multicolumn{1}{c}{ Accuracy Measures } & \multicolumn{1}{c}{ No. } \\
\hline Clauses & 18 \\
Error-Free Clauses & 14 \\
Percentage of Error-Free Clauses & $77.77 \%$ \\
Fluency Measures & No. \\
Words per Task & 87 \\
Words per Minute & 8.7 \\
Words per Clause & 4.83 \\
\hline
\end{tabular}

The table shows the way the measures analyzed were put together to later compare them and explore if there was any development in terms of AF. To ensure the consistency and accuracy of the measures, all of the data were coded and measured separately by each researcher, and correlation coefficients of $r>.90$ were observed for the two measures.

Concerning the qualitative data obtained from the questionnaires completed after each task, Gery and Bernard (2000) made reference to the repetition of words, metaphors identification, and shifts in content as a resource to identify participants' constructs and meaning making. Based upon this idea, we only considered those segments in which the participants appeared to be voicing their perceptions of the tasks, performance, and how these were potentially influenced by their process of becoming familiar with the procedural design of the tasks. 


\section{Results}

This section presents the results of the study in order to answer the research question (i.e. to what extent does the procedural repetition of narrative tasks based upon short animated video input shape students' accuracy and fluency?). Graphs are used in this section to present the results and tendencies more visually. To better understand how the nature of the tasks and the repeated design shape the students' AF, data from the questionnaires are presented and discussed.

The figure below summarizes the results concerning fluency gathered from Participant 1 across all four sessions.

\section{Figure 1}

Participant 1's fluency levels

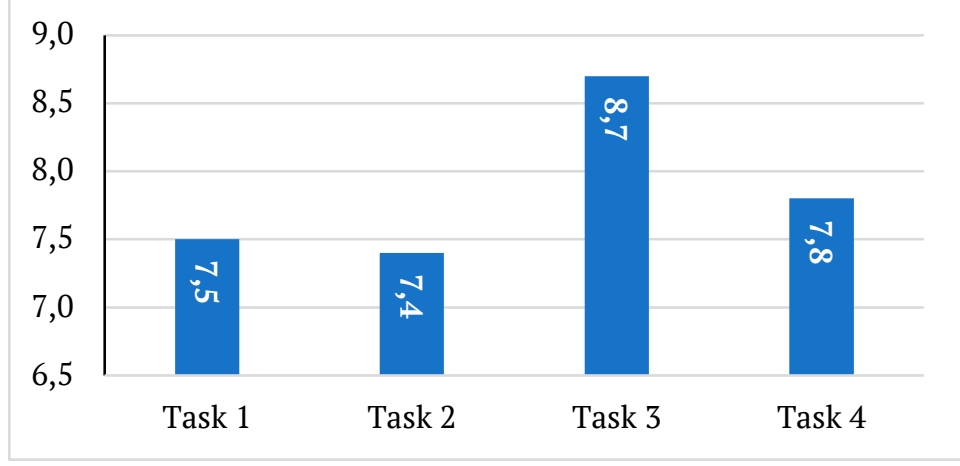

As can be seen in Figure 1, Participant 1's fluency levels varied across the four tasks. In Task 2, it was documented that the fluency level slightly decreased ( 7.4 words per minute) compared to Task 1 (7.5 words per minute). Interestingly, the fluency level steeply increased in Task 3 (8.7 words per minute). Moreover, in Task 4, the fluency level sharply dropped ( 7.8 words per minute). A similar tendency can be found in this participant's accuracy levels across the four narrative tasks. This is shown in Figure 2.

\section{Figure 2}

Participant 1's accuracy levels

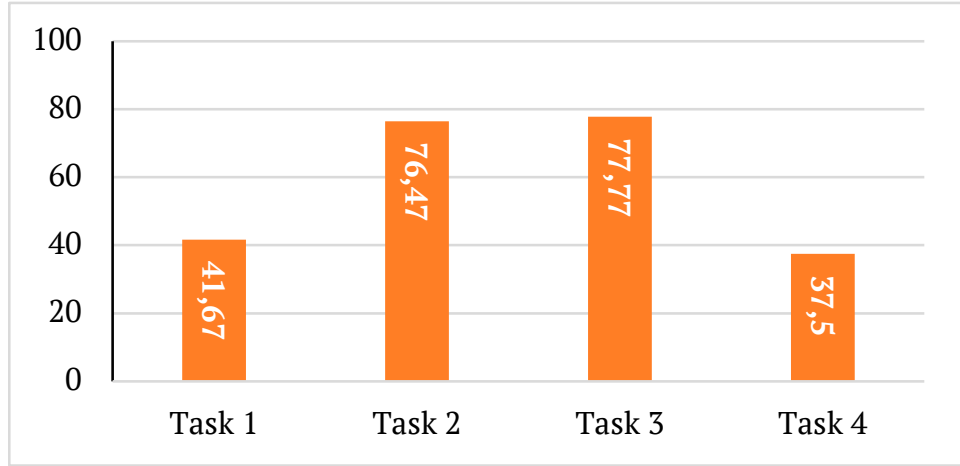

As with the fluency levels, it can be seen that the accuracy levels varied significantly. Moreover, accuracy was considerably low in Task 1 (41.67\%). Interestingly, we can see a significant increase in Tasks 1 and 2 (41.67\% and $76.47 \%$, respectively), and a slight increase in Tasks 2 and 3. Moreover, as with fluency, there was a steep decline in accuracy in Task 4 (37.5\%). If we compare Figures 1 and 2, we can generally see that both fluency and accuracy tended to increase steadily in Tasks 2 and 3, but the levels considerably decreased in Task 4. As suggested by the data collected from the questionnaires, the increases in fluency and accuracy could be explained by the students' familiarity with the content in the video for Task 3. For example, Participant 1 after Task 3 suggested the following: 
I liked it more, also I think the topic was more familiar to me. (Participant 1, Task 3)

Thus it seems possible that the participant's familiarity with the message content of the short animated videos played a role in increasing both fluency and accuracy in Task 3. As we will see below, this suggestion is also borne out by the questionnaire data themselves, which suggested that in Task 4, the participants felt a disconnection between their own previous experiences and the content of the video played for that task, contrary to the familiarity they claimed to have with the content of Task 3.

The next figure shows the fluency performance of Participant 2 throughout the four tasks.

\section{Figure 3}

Participant 2's fluency levels

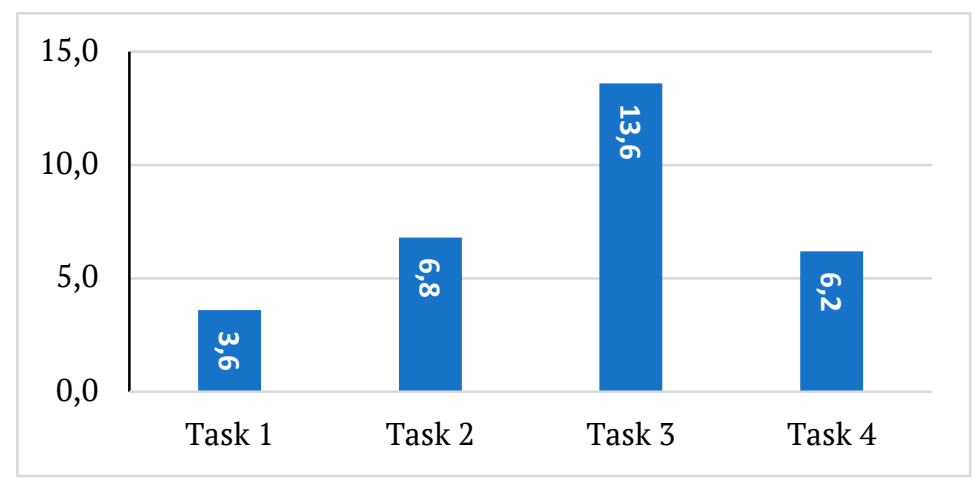

Figure 3 shows that Participant 2's fluency levels varied across the four tasks. In contrast to Participant 1, a significant increase in Participant 2's fluency can be seen from Task 1 to Task 2 (6.8 words per minute in Task 2 compared to 3.6 words per minute in Task 1). Again, there was a marked rise in the fluency level in Task 3 (13.6 words per minute), and then a sharp drop in Task 4 . However, a different pattern can be observed in Participant 2 's accuracy levels. They are displayed in Figure 4.

\section{Figure 4}

Participant 2's accuracy levels

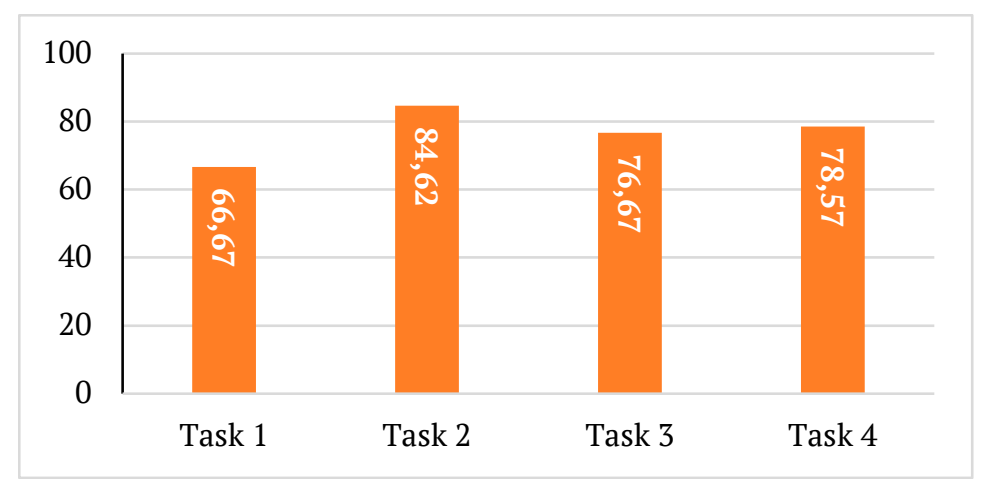

As in Figure 2 (Participant 1's accuracy levels), there was an increase in accuracy from Task 1 to Task 2 (66.67\% to $84.62 \%$ of error-free clauses). However, accuracy decreased slightly in Task 3 (76.67\%), but then increased again in Task 4 (78.57\%). In general, we can suggest that it was again Task 3 that promoted AF. It is therefore likely that the familiarity that the students claimed to have with the message content of the animated video in Task 3 appeared to promote the AF of their written constructions. For example, Participant 2 suggested the following:

It was a topic of which I knew a bit more of vocabulary and that helped me. (Participant 2, Task 3) 
Here, Participant 2 claims that he was more familiar with the vocabulary words that appeared in the dialogues. Therefore, this seems to have helped him construct more accurate and fluent utterances than in the other three tasks. The video was about a short argument between a mother and her son because the child was playing a video game instead of doing his chores. To the majority of the participants, this topic was linked to their own previous experiences. Hence, they felt more comfortable writing about it because they knew more vocabulary and they understood the situation clearly. However, in Task 2, the student showed their highest accuracy (84.62\%), but rather low fluency compared to Task 3 (6.2 compared to 13.6 words per minute). It is possible to hypothesize that for cognitively demanding tasks, such as narrative tasks, fluency and accuracy may compete with each other when students are not familiar with the message content of the task. In other words, in unfamiliar tasks that require high levels of attention to be performed, students will have to prioritize where to allocate their attention (Skehan, 1998), in this case, fluency or accuracy. This suggestion is also supported by the data of Participants 4 and 5 , who also appeared to prioritize only one dimension in Task 2 . What is interesting in Figures 3 and 4 is the same low levels of fluency and accuracy in Task 4 compared to Tasks 2 and

3. Regarding Task 4, Participant 2 stated that they did not feel any familiarity with the plot and the story.

The dialogues and the situation were a bit weird and strange for me in this video. (Participant 2, Task 4)

These low levels could be attributed to the participant's feelings of disconnection with the content, which may have shaped the way and speed in which words were produced, as it takes longer to process new information and organize the ideas.

A similar pattern to Participants 1 and 2 can be found in Figure 5, which shows Participant 3's fluency levels across the four tasks.

\section{Figure 5}

Participant 3's fluency levels

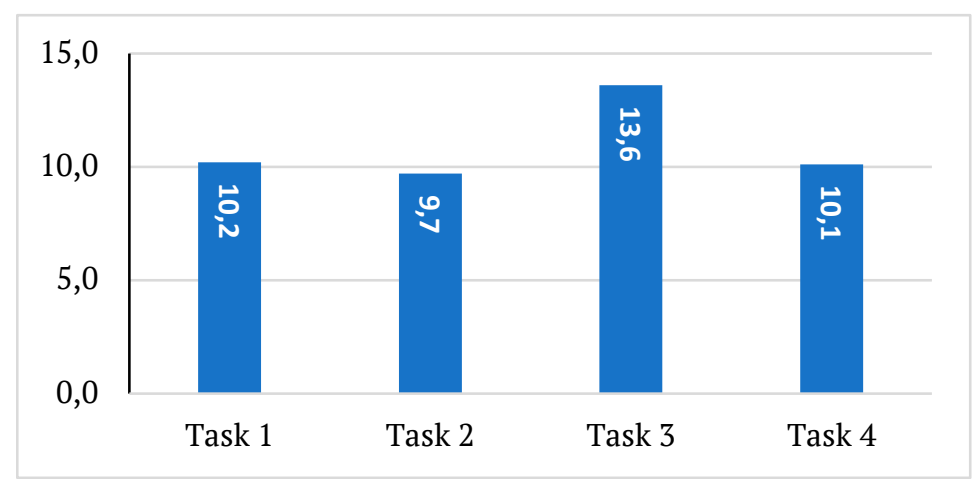

As in Figure 1, there was a slight decrease in the fluency levels when we compared Tasks 1 and 2 (9.7 compared to 10.2 words per minute). In the questionnaire administered after Task 2, the participant stated that they experienced some difficulties understanding the plot, as suggested below.

\section{[...] the story appeared strange to me for being fictional. (Participant 3, Task 2)}

What stands out from this figure is that Participant 3's fluency significantly rose in Task 3. Moreover, fluency then fell sharply in Task 4. A similar pattern in terms of accuracy can be seen in Tasks 3 and 4 shown in Figure 6 below. 


\section{Figure 6}

Participant 3's accuracy levels

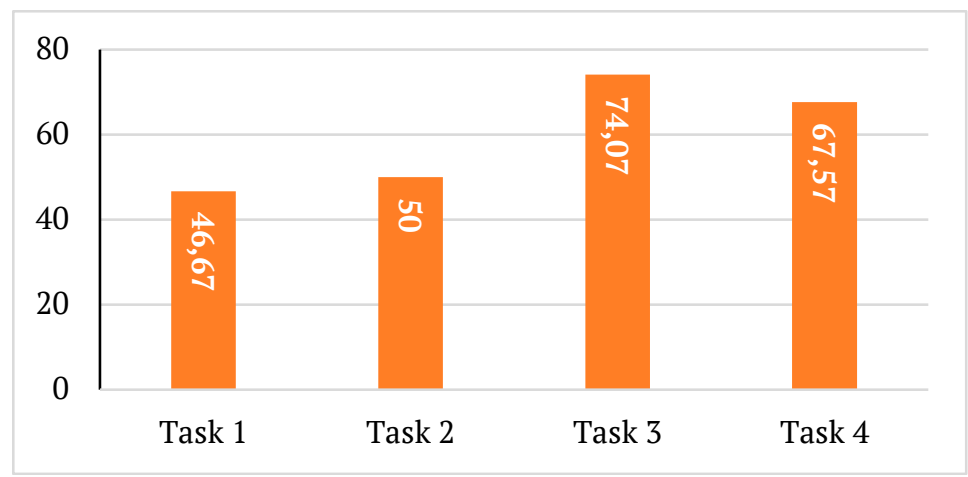

From the figure above we can remark that accuracy increased slightly in Task 2 (50\% error-free clauses). As we might expect, Participant 3's accuracy steeply rose in Task 3. As with Participants 1 and 2, we can link the accuracy performance to the familiarity with the task and the video content and dialogues. In the excerpt provided below, the participant suggests that he was easily able to follow the video dialogues.

Of easy interpretation, which makes the explanation about it more simple. (Participant 3, Task 3)

It is possible therefore that the students' familiarity with the content of the videos and dialogues enabled them to retain the visual input and, as a consequence, produce more fluent and accurate constructions in Task 3 than in the other three tasks. If we compare the participant's performance in Tasks 3 and 4 , we can again observe a decrease in terms of accuracy. The last task showed a decrease in accuracy due to some disengagement from the vocabulary and dialogues used in the videos, as suggested in Participant 3's response below.

For me there was not much relation, not in the fact of the content of the video. (Participant 3, Task 4)

This is not surprising as the fourth video used was particularly surreal and abstract. Therefore, the participants stated that they felt a lack of connection, which seems to be reflected in the fluency and accuracy reductions. This is supported by Participant 4's data as shown in Figures 7 and 8 below.

\section{Figure 7}

Participant 4's fluency levels

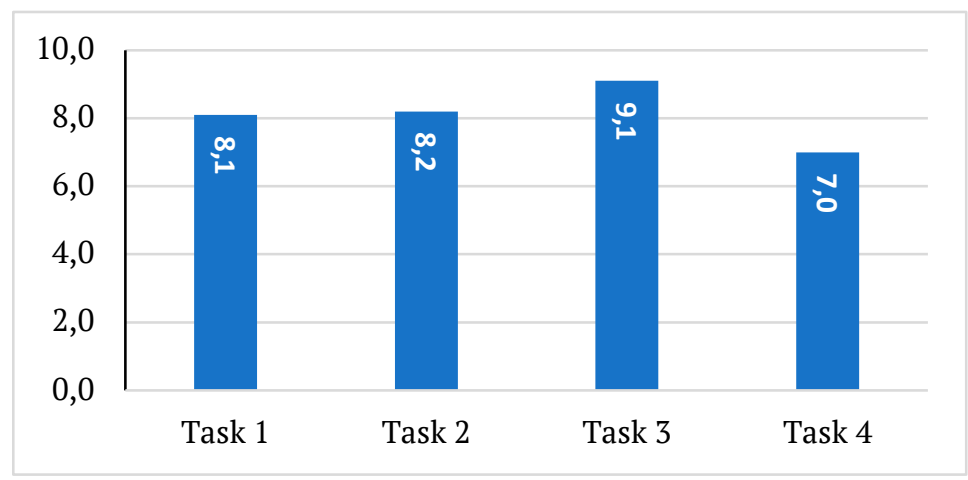

The figure shows that there was a steady increase in the levels of fluency in Tasks 1 to 3 (from 8.1 to 9.1 words per minute). Again, in Task 3, the participant showed the highest fluency level (9.1), but the lowest fluency in Task 4 (7.0). A similar pattern can be found in the accuracy levels in Tasks 3 and 4, as presented in Figure 8. 
Figure 8

Participant 4's accuracy levels

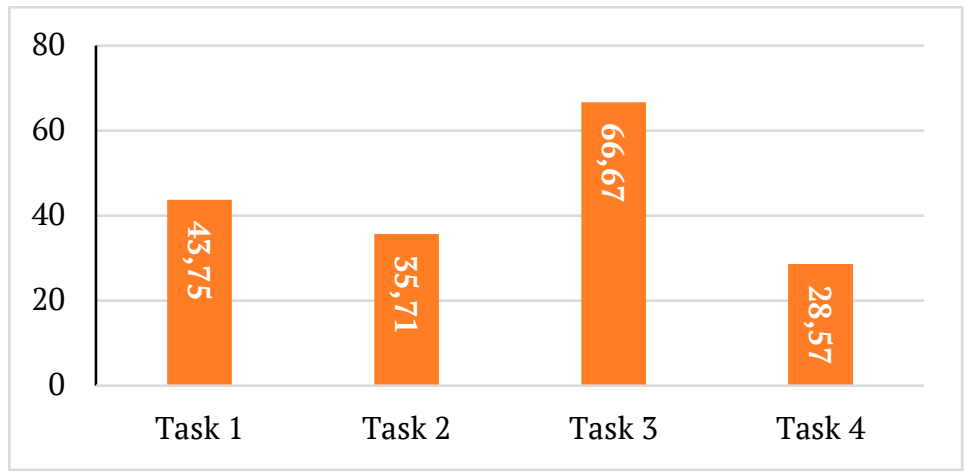

Similar to Participant 1 (Figure 2), Figure 8 shows a slight decrease in accuracy in Task 2 (35.71\% compared to 43.75\% in Task 1), but a gradual increase in terms of fluency (Figure 7). In the questionnaires after the sessions, Participant 4 provided the following response when asked how he felt about his performance:

When I was watching the video, I knew what I wanted to put down, but after starting to write I felt a bit nervous. (Participant 4, Task 1)

Therefore, we can suggest that when students are in the process of becoming familiar with a new task, they may experience high levels of anxiety which, alongside their limited attentional capacities (Lutz \& Huitt, 2003; Skehan, 2009), potentially shape their performance as evident in their fluency and accuracy levels. As in the cases of Participants 1, 2, and 3, Participant 4 achieved the highest AF levels in Task 3. It is again possible to suggest that this represents a connection with the content; that is, the students' familiarity with the vocabulary and the content shown in the video (Task 3) contributed to the production of more fluent and accurate structures. However, fluency and accuracy levels significantly decreased in Task 4 . In the questionnaire used after Task 4, there was a question posed about the participant's opinion regarding the connection between the content and the written production. The participant's response was:

There is not much relation. (Participant 4, Task 4)

With this response, the participant referred to a feeling of disconnection with the video content in the last session. This appeared to have affected their fluency and accuracy levels, as it might have taken longer for the participant to process the writing in terms of words and structures.

Finally, Figures 9 and 10 show the fluency and accuracy levels of Participant 5 across the four narrative tasks.

\section{Figure 9}

Participant 5's fluency levels

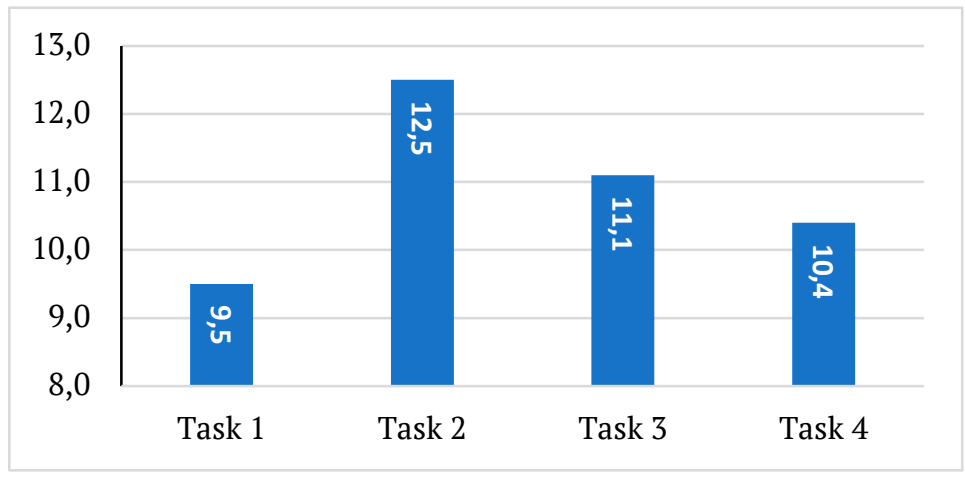


As with in the fluency levels of Participants 2 and 4, Participant 5 constructed more fluent sentences in Task 2 than in Task 1 (12.5 compared to 9.5 words per minute). Interestingly, in Task 2, this participant showed the most fluent constructions in contrast to the other participants, who tended to have the highest fluency levels in Task 3. As with the previous participants, this participant's fluency decreased in Task 4. A different pattern of accuracy can be seen in the figure below.

\section{Figure 10}

Participant 5's accuracy levels

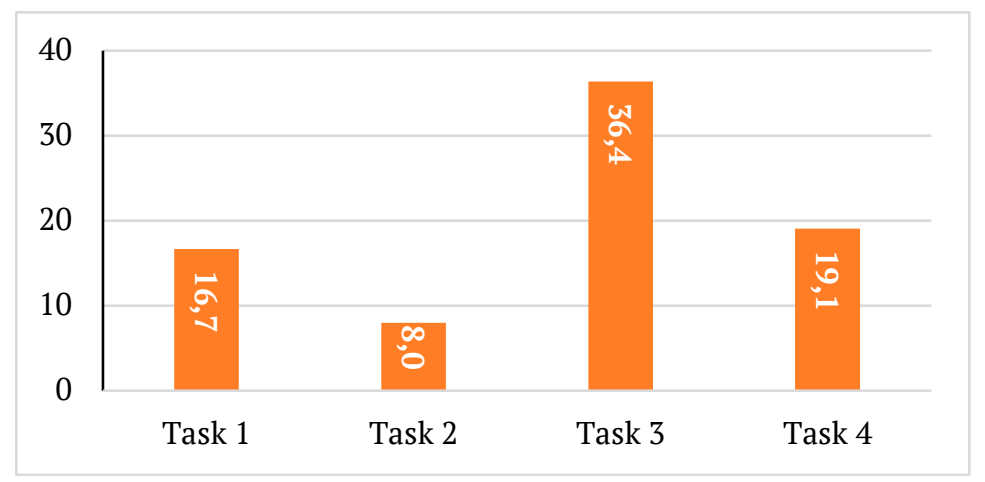

In contrast to fluency, there was a noticeable decrease in accuracy in Task 2. It can be interpreted that because of limited attentional capacities (Skehan, 1998, 2009), the participant was compelled to focus on writing as much as possible in the time assigned, affecting in turn the accuracy level because less time was dedicated to think about the correction of language structures. That is, dedicating less time to planning often results in less accurate writing (Ahmadian \& Tavakoli, 2010; Skehan, 1998). In Task 3, there was a sharp increase in the accuracy level, which can again be attributed to the participant's familiarity with the content of the video, as suggested below.

Comfortable, it is each individual who chooses how to write what it was seen in the videos.

(Participant 5, Task 3)

As suggested in her response, the participant seemed to be comfortable writing about the topic provided in Task 3. Moreover, the relation between the content and the written production was also highlighted, suggesting that the content of the videos allowed them to be creative in terms of language use when performing the task. As shown in Task 4, both accuracy and fluency decreased considerably. Once again, this can be related to the participant's lack of familiarity with the content and the low number of dialogues presented in the video.

In my case I tried to remember the words that would complement, because they contained little dialogue. (Participant 5, Task 4)

Therefore, the participant's inability to retrieve words that could be used to perform and accomplish Task 4 appeared to have resulted in lower levels of fluency and accuracy than in Task 3.

In summary, the results discussed in this section show that the five participants' AF levels varied considerably across the four narrative tasks. Despite this variability, it was possible to identify some trends that showed that AF improved in some tasks, namely, Tasks 2 and 3. However, when the repetition practice combines with students' lack of familiarity with the content of a task, their AF may be affected in unpredictable ways.

\section{Discussion}

The purpose of the present study was to understand the effect of the procedural repetition of four narrative tasks on five students' AF with stimulated recalls from questionnaires following Fukuta's (2016) recommendation. In general, the findings showed that both fluency and accuracy tended to be considerably lower in the first task. This can be explained by the fact that, in this context, the students had not been asked to perform writing tasks to narrate stories seen on videos. Therefore, we can suggest that the students were not 
familiar with the design of the first task and thus showed low levels of AF. When students perform unfamiliar and challenging tasks, their AF levels tend to decrease considerably (Qiu, 2019), because the (cognitive and instructional) demands of the task compel them to prioritize the complexity of their language constructions (Skehan, 2009, 2018). In his Trade-off Hypothesis, Skehan (2009) explained that students' inability to promote meaning and form simultaneously is believed to be a consequence of limitations in their attentional capacities, which compel them to make choices on being complex, being accurate, and/or being fluent.

After the repetition of the first task in this study, it was possible to see higher levels of AF, particularly in Tasks 2 and 3. This finding is aligned with Khezrlou's (2020) and Lynch and Maclean's (2000, 2001) studies, which also showed that task repetition tends to increase both fluency and accuracy, but in oral skills. Ahmadian and Tavakoli (2010) contended that the focus of tasks on meaning encourages students to prioritize meaning over form. This may be explained by the fact that processing meaning (in our study, the stories of the videos) requires fewer attentional resources (Muranoi, 2007). However, the fact that the students in this study were able to repeat the procedure of the narrative tasks at weekly intervals seems to have enabled them to shift their attention to more fluent and accurate written formulations (Bygate, 1996). We can, consequently, hypothesize that in the planning process of their writing system (Kellogg, 1996), as in Task 1 of our study, students scanned their memory for automated aspects of their language to deal with the task (Bygate, 1999; Qui, 2019), and stored traces of both meaning and forms (e.g., items, images or content) temporarily in their memory (Muranoi, 2007). In the second opportunity to perform the task, the students were more cognitively prepared and reactive concerning the meaning and form previously stored in the memory for their task performance (Bygate \& Samuda, 2005). Since the students were in the process of becoming familiar with the implementation procedures of the task and already know what they would say in their task performance, this allowed them to have more processing space available to shift their attention to the formulation stage of the language required to express their ideas (Ellis, 2003), with the result that both accuracy and fluency are increased.

However, the figures indicated that there was a significant amount of fluctuation in terms of the AF levels in Tasks 2 and 3. We believe that in Task 2, the students were in the process of becoming familiar with the task procedures. This created a dynamic interaction between fluency and accuracy motivated by their limited attentional capacities (Skehan, 1998, 2009). These results provide further evidence in support of the notion of limited and selective attentional capacities (Ahmadian \& Tavakoli, 2010; Skehan, 1998), in that the students were able to attend to fluency or accuracy but not the two simultaneously. According to Huitt (2003), when students perform an unfamiliar task, their control mechanism (for storing, encoding, and producing information) requires more processing and attentional resources. This means that they would need to dedicate more time to the planning and translating processes of the writing system (Kellogg, 1996), which would limit their focus on fluency or accuracy.

Despite the variability, it was possible to see a global tendency for higher AF in Task 3. As suggested in the students' responses, they were familiar with the story in the video and the vocabulary in the dialogues. Our findings of high fluency levels on this task are supported by Chang (1999), who found that familiarity with a topic enhanced fluency. Similarly, Skehan and Foster (1999) and Robinson (2001) found that when students have a schema of a familiar area or structure of a story, fluency levels increase significantly. Drawing on this claim, it may be the case that the schema of the procedural design of the tasks promoted the levels of both fluency and accuracy in Task 3 (see also Van de Guchte, Braaksma, Rijlaarsdam, \& Bimmel, 2016). Hence, it could be conceivably hypothesized that content familiarity is a factor that may assist students in producing accurate and fluent written constructions because content familiarity frees up the load from the cognitive processes of the writing system (Kellogg, 1996), which are demanded in order to perform the task, and thus allows them to direct their attention to construct more fluent and accurate sentences (Skehan, 2014). This is also supported by Bui (2014), Bui and Huang (2018), and Lambert and Robinson (2014) who contended that content familiarity eases the cognitive load and thus benefits L2 production. In a similar vein, in the schema theory, Bartlet (1932) suggested that language production becomes easier when familiar topics or content are stored in background knowledge because this knowledge in schema interferes and restructures the interpretation of new information. With respect to Task 4, the five students' AF levels tended to fall considerably. As suggested in the questionnaire data, the students stated that they did not feel any connection with the content of the video because it contained fewer dialogues, and the story in the video was perceived to be surreal. Thus, it can be suggested that their lack of familiarity with the content and dialogues may have negatively 
influenced the students' AF levels in this last task, despite the experience gained through becoming familiar with the procedures from the previous tasks.

Taken together, the initial results of this study suggest a potential interplay among the AF areas, procedural task repetition, and content familiarity. In other words, our evidence suggests that the procedural repetition of tasks and content familiarity could be beneficial for encouraging AF simultaneously. However, if this practice combines with the students' lack of familiarity with the content, it seems to initiate a dynamic interaction between fluency and accuracy motivated by their competition for attention (Skehan, 1998). In contrast, when students are familiar with the content of tasks, it may be the case that task repetition may free up students' cognitive load to direct their attention to both the fluency and accuracy of their written constructions. The present study thus raises the possibility that in order to facilitate students with "a system which remains open to noticing and to change while at the same time making some gains in terms of fluency and real-time language processing" (Skehan, 1998, p 91), language teaching should provide them with opportunities for task repetition and different degrees of content familiarity simultaneously (Qiu, 2019).

\section{Conclusion}

The present study set out to examine the effect of the procedural repetition of four narrative tasks using short animated videos on five students' AF in their classroom environment. Four narrative tasks were designed following the same procedural structure, that is, the four tasks shared the same design but different content provided by short animated videos. To understand the students' perceptions of the tasks and content familiarity, a questionnaire was administered as a stimulated recall at the end of each writing task.

Since the narrative tasks were new to the students, we expected that the repetition of the tasks would lead to a progressive rise in the levels of AF. However, the findings of this study indicated that the procedural repetition of the narrative tasks appeared to improve the fluency and accuracy of the five students' written constructions only on some tasks and to some extent. Moreover, when combined with the students' familiarity with the content of the videos, this repetition practice created significant fluctuations in the levels of AF. Particularly, when the students stated that the content of the videos was familiar to them, high levels of both fluency and accuracy were observed in the data; the opposite happened when the students claimed that the content was not familiar to them.

The findings of this study have practical implications for the EFL classroom. Firstly, task repetition should be carried out in language classrooms in order to promote students' L2 performance and to enhance language development when dealing with cognitively challenging tasks. In order to maximize the benefits of task repetition, students should first perform tasks where the content and vocabulary are familiar to them. This suggestion was supported by our data, which exposed that the highest AF levels were found in the tasks where the content appeared to be familiar to the students. However, in order to foster student autonomy and L2 development, students could gradually perform tasks that are more challenging in terms of content processing. We believe that this gradual experience with new tasks and content will enable them to develop and rely on the language resources that are beneficial for their L2 performance. This suggestion relates not only to narrative tasks but to tasks that are unfamiliar to students or cognitively challenging.

The present study was subject to some potential weaknesses. For example, this small-scale study was exploratory in nature and its objective was not to generalize the findings, but to examine the potential role of task repetition in a context where students are seen to struggle with tasks whose instructional and cognitive demands are considered to be challenging. Moreover, the lack of control regarding the content of the videos appear to have initiated significant fluctuations in the levels of AF across the tasks. Finally, this study included a small amount of data from five participants who performed a narrative task over four sessions. Notwithstanding the exploratory nature of the study and the relatively limited sample, we believe that task repetition and students' content familiarity can be used by teachers as practices that can be manipulated and adapted to promote L2 performance and thus development. These findings of course are not conclusive; more research needs to be conducted in order to understand how teachers and students can maximize the use of task procedural repetition in their contexts. We hope that this study has contributed to this purpose. 


\section{Conflicts of interest}

The authors declare that they have no conflicts of interest.

\section{References}

Abdi, M., Eslami, H., \& Zahedi, Y. (2012). The impact of pre-task planning on the fluency and accuracy of Iranian EFL learners' oral performance. Procedia-Social and Behavioral Sciences, 69, 2281-2288. https://doi. org/10.1016/j.sbspro.2012.12.199

Ahmadian, M. J. (2012). Task repetition in ELT. ELT Journal, 66(3), 380-382. https://doi.org/10.1093/elt/ccs020

Ahmadian, M. J., \& Tavakoli, M. (2010). The effects of simultaneous use of careful online planning and task repetition on accuracy, complexity, and fluency in EFL learners" oral production. Language Teaching Research, 15(1), 35-59. https://doi.org/10.1177\%2F1362168811425433

Atkinson, R., \& Shiffrin, R. (1968). Human memory: A proposed system and its control processes. In K. Spence, \& J. Spence (Eds.), The psychology of learning and motivation: Advances in research and theory (vol. 2, pp. 89195). Academic Press.

Bartlett, F. C. (1932). Remembering: A study in experimental and social psychology. Cambridge University Press.

Bui, G. (2014). Task readiness: Theoretical framework and empirical evidence from topic familiarity, strategic planning, and proficiency levels. In P. Skehan (Ed.), Processing perspectives on task performance (pp. 63-93). John Benjamins.

Bui,G., \& Huang,Z.(2018).L2fluencyasinfluencedbycontentfamiliarityandplanning:performance,measurement, and pedagogy. Language Teaching Research, 22(1), 94-114. https://doi.org/10.1177\%2F1362168816656650

Bygate, M. (1996). Effects of task repetition: Appraising the developing language of learners. In J. Willis, \& D. Willis (Eds.), Challenge and change in language teaching (pp. 136-146). Heinemann.

Bygate, M. (1999). Task a context for the framing, reframing and unframing of language. System, 27(1), 3338. https://doi.org/10.1016/s0346-251x(98)00048-7

Bygate, M. \& Samuda V. (2005). Integrative planning through the use of task repetition. In R. Ellis (Ed.), Planning and task performance in second language (pp. 37-73). John Benjamins.

Chang, Y. F. (1999). Discourse topics and interlanguage variation. In P. Robinson (Ed.), Representation and process: Proceedings of the 3rd Pacific Second Language Research Forum (vol. 1, pp. 235-241). PacSLRF.

Ellis, R. (2003). Task-based language learning and teaching. Oxford University Press.

Ellis, R. (2005). Planning and task-based performance: Theory and research. In R. Ellis (Ed.), Planning and task performance in second language (pp. 3-34). John Benjamins.

Ellis, R. (2009). The differential effects of three types of task planning on the fluency, complexity and accuracy in L2 oral production. Applied Linguistics, 30(4), 474-509. https://doi.org/10.1093/APPLIN\%2FAMP042

Ellis, R., \& Yuan, F. (2004). The effects of planning on fluency, complexity, and accuracy in second language narrative writing. Studies in Second Language Acquisition, 26(1), 59-84. https://doi.org/10.1017/ S0272263104026130

Flower, L., \& Hayes, J. (1980). The dynamics of composing: Making plans and juggling constraints. In L. Gregg, \& F. Steinberg (Eds.), Cognitive processes in writing (pp. 31-50). Lawrence Erlbaum Associates.

Foster, P. (1999). Task-based language learning and pedagogy. ELT Journal, 53(9), 69-70. https://doi. org/10.1057/9780230522961_2

Fukuta, J. (2016). Effects of task repetition on learners' attention orientation in L2 oral production. Language Teaching Research, 20(3), 321-340. https://doi.org/10.1177\%2F1362168815570142

Gass, S., Mackey, A., Alvarez-Torres, M. J., \& Fernandez-Garcia, M. (1999). The effects 89 of task repetition on linguistic output. Language Learning, 49(4), 549-581. https://doi.org/10.1111/0023-8333.00102

Gery, W. R., \& Bernard, H. R. (2000). Data management and analysis methods. In N. K. Denzin, \& Y. S. Lincoln (Eds.), Handbook of qualitative research (pp. 835-850). Sage Publications.

Ghavamnia, M., Tavakoli, M., \& Esteki, M. (2013). The effect of pre-task and online planning conditions on complexity, accuracy, and fluency on EFL learners' written production. Porta Linguarium, 20, 31-43. https:// doi.org/10.30827/digibug.29559

Hamp-Lyons, L., \& Heasly, B. (2006). Study writing (2nd ed.). Cambridge University Press.

Huitt, W. (2003). The information processing approach to cognition. Educational Psychology Interactive. Valdosta State University. http://www.edpsycinteractive.org/topics/cognition/infoproc.html

Kellogg, R. T. (1996). A model of working memory in writing. In C. M. Levy, \& S. Ransdell (Eds.), The science of 
writing (pp. 57-71). Lawrence Erlbaum Associates.

Kellogg, R. T., Whiteford, A. P., Turner, C. E., Cahill, M., \& Mertens, A. (2013). Working memory in written composition: An evaluation of the 1996 Model. Journal of Writing Research, 5(2), 159-190. https://doi. org/10.17239/jowr-2013.05.02.1

Khezrlou, S. (2019). Task repetition and corrective feedback: The role of feedback types and structure saliency. English Teaching and Learning, 43(2), 213-233. https://doi.org/10.1007/s42321-019-00025-2

Khezrlou, S. (2020). The role of task repetition with direct written corrective feedback in L2 writing complexity, accuracy and fluency. Journal of Second Language Studies, 3(1), 31-54. https://doi.org/10.1075/jsls.19025.khe

Kuhi, D., Rasuli, M. A., \& Deylami, Z. (2014). The effects of type of writing on accuracy, fluency and complexity across proficiency. Social and Behavioral Sciences, 98, 1036-1045.https://doi.org/10.1016/j.sbspro.2014.03.514

Lambert, C., Kormos, J., \& Minn, D. (2017). Task repetition and second language speech processing. Studies in Second Language Acquisition, 39(1), 167-196. https://doi.org/10.1017/S0272263116000085

Lambert, C., Robinson, P. (2014). Learning to perform narrative tasks: A semester-long classroom study of L2 task sequencing effects. In M. Baralt, R. Gilabert, P. Robinson (Eds.), Task sequencing and instructed second language learning (pp. 207-230). Bloomsbury Academic.

Larsen-Freeman, D. (2006). The emergence of complexity, fluency, and accuracy in the oral and written production of five chinese learners of English. Applied Linguistics, 27(4), 590-619. https://doi.org/10.1093/ applin/aml029

Lutz, S., \& Huitt, W. (2003). Information processing and memory: Theory and applications. In W. Huitt (Ed.), Becoming a brilliant star: Twelve core ideas supporting holistic education (pp. 25-43). IngramSpark.

Lynch, T., \& Maclean, J. (2000). Exploring the benefits of task repetition and recycling for classroom language learning. Language Teaching Research, 4, 221-50. https://doi.org/10.1177\%2F136216880000400303

Lynch, T. \& Maclean, J. (2001). Effects of immediate task repetition on learners' performance. In M. Bygate, P. Skehan, \& M. Swain (Eds.), Researching pedagogic tasks, second language learning, teaching and testing (pp. 99-118). Longman.

Manchón, R.M. (2014). Learning and teaching writing in the FL classroom: Fostering writing-to-learn approaches. In P. Driscoll, E. Macaro, \& A. Swarbrick (Eds.), Debates in modern language education (pp. 96-107). Routledge.

Manchón, R. M, \& Roca de Larios, J. (2011). Writing to learn in FL contexts: Exploring learners' perceptions of the language learning potential of L2 writing. In R. M. Manchón (Ed.), Learning to write and writing to learn in an additional language (pp. 181-207). John Benjamins.

Manchón, R. M, \& Vasylets, O. (2019). Language learning through writing: Theoretical perspectives and empirical evidence. In J. W. Schwieter, \& A. Benati (Eds.), The Cambridge handbook of language learning (pp. 341-362). Cambridge University Press.

Muranoi, H. (2007). Output practice in the L2 classroom. In R. DeKeyser (Ed.), Practice in second language learning: Perspectives from applied linguistics and cognitive psychology (pp. 51-84). Cambridge University Press.

Ong, J., \& Zhang, L. J. (2010). Effects of task complexity on fluency and lexical complexity in EFL students' argumentative writing. Journal of Second Language Writing, 19, 218-233. https://doi.org/10.1016/j. jslw.2010.10.003

Qiu, X. (2019). Functions of oral monologic tasks: Effects of topic familiarity on L2 speaking performance. Language Teaching Research, 1-20. https://doi.org/10.1177/1362168819829021

Robinson, P. (2001). Task complexity, task difficulty, and task production: Exploring interactions in a componential framework. Applied Linguistics, 22(1), 27-57. https://doi.org/10.1093/applin/22.1.27

Robinson, P., \& Gilabert, R. (2007). Task complexity, the Cognition Hypothesis and second language learning and performance. International Review of Applied Linguistics in Language Teaching, 45(3), 161-176. https://doi. org/10.1515/IRAL.2007.007

Skehan, P. (1996). A framework for the implementation of task-based instruction. Applied Linguistics, 17(1), 3861. https://doi.org/10.1093/applin/17.1.38

Skehan, P. (1998). A cognitive approach to language learning. Oxford University Press.

Skehan, P. (2003). Task-based instruction. Language Teaching, 36(1), 1-14. https://doi.org/10.1017/ S026144480200188X

Skehan, P. (2009). Modelling second language performance: Integrating complexity, accuracy, fluency, and lexis. Applied Linguistics, 30(4), 510-532. https://doi.org/10.1093/applin/amp047

Skehan, P. (2014). Processing perspectives on task performance.John Benjamins.

Skehan, P. (2018). Second language task-based performance: Theory, research, assessment. Routledge.

Skehan, P., \& Foster, P. (1999). The influence of task structure and processing conditions on narrative retellings. Language Learning, 49(1), 93-120. https://doi.org/10.1111/1467- 9922.00071 
Sohn, M., \& Anderson, J.R. (2001). Task preparation and task repetition: Two-component model of task switching. Journal of Experimental Psychology: General, 130(4), 764-778. https://doi.org/10.1037//0096-3445.130.4.764

Tavakoli, P., \& Foster, P. (2008). Task design and second language performance: The effect of narrative type on learner output. Language Learning, 61(1), 37-72. https://doi.org/10.1111/j.1467-9922.2011.00642.x

Van de Guchte, M., Braaksma, M., Rijlaarsdam, G., \& Bimmel, P. (2016). Focus on form through task repetition in TBLT. Language Teaching Research, 20(3), 300-320. https://doi.org/10.1177\%2F1362168815609616

Wolfe-Quintero, K., Inagaki, S., \&. Kim, H.-Y. (1998). Second language development in writing: Measures of fluency, accuracy, and complexity. University of Hawaii Press.

Yuan, F., \& Ellis, R. (2003). The effects of pre-task planning and on-line planning on fluency, complexity and accuracy in L2 oral production. Applied Linguistics, 24(1), 127. https://doi.org/10.1093/applin/24.1.1 


\section{Appendix}

\section{Questionnaires for Sessions 1 to 4}

Por favor, responde lo más claramente posible a las siguientes preguntas:

1. ¿Cómo te sentiste durante el desarrollo de esta actividad?

2. ¿Cómo percibiste tu desempeño durante esta actividad?

3. ¿Qué diferencia notaste en tu desempeño en esta sesión?

4. ¿Qué piensas sobre este video, comparado con los previamente mostrados, en relación a la promoción de la escritura?

5. ¿Cómo crees que influya el uso de videos cortos en la promoción de la narración escrita en el idioma inglés?

\section{Translated version:}

Please respond, as clearly as possible, to the next questions:

1. How did you feel during the development of the tasks?

2. How did you perceive your own performance during the tasks?

3. What differences did you notice in your performance in this session?

4. What do you think about this video, compared to the ones previously shown, in relation to writing encouragement?

5. How do you think that the use of short videos influences the promotion of narrative writing? 